\title{
BMJ Open Sex-specific trends in smoking prevalence over seven years in different Austrian populations: results of a time- series cross-sectional analysis
}

\author{
Thomas Ernst Dorner (D) , ${ }^{1,2}$ Helmut Brath, ${ }^{3}$ Alexandra Kautzky-Willer (D) ${ }^{4}$
}

To cite: Dorner TE, Brath $\mathrm{H}$, Kautzky-Willer A. Sex-specific trends in smoking prevalence over seven years in different Austrian populations: results of a time-series crosssectional analysis. BMJ Open 2020;10:e035235. doi:10.1136/ bmjopen-2019-035235

- Prepublication history for this paper is available online. To view these files, please visit the journal online (http://dx.doi. org/10.1136/bmjopen-2019035235).

Received 23 0ctober 2019 Revised 22 July 2020

Accepted 07 August 2020

Check for updates

(C) Author(s) (or their employer(s)) 2020. Re-use permitted under CC BY-NC. No commercial re-use. See rights and permissions. Published by BMJ.

${ }^{1}$ Unit Lifestyle \& Prevention, Department for Social and Preventive Medicine, Centre for Public Health, Medical University Vienna, Vienna, Austria

${ }^{2}$ Social Insurance Fund for

Public Service, Railway and

Mining Industries, Sitzenberg-

Reidling, Austria

${ }^{3}$ Diabetes Outpatient Clinic, Health Centre Favoriten, Vienna,

Austria

${ }^{4}$ Gender Medicine Unit, Division of Endocrinology and Metabolism, Department of Internal Medicine III, Medical University Vienna, Vienna, Austria

\section{Correspondence to}

Professor Thomas Ernst Dorner; thomas.dorner@meduniwien. ac.at

\section{ABSTRACT}

Objectives Aim of this study was to examine trends over time in smoking status in men and women, and in subgroups, in Austria, a country with poor smoking regulation policies.

Design and participants Two cross-sectional surveys (Austrian Health Interview Surveys for 2007 and 2014), each with more than 15000 participants from the general population, aged $\geq 15$ years.

Outcome measures Prevalence of self-reported daily smoking. ORs for daily smoking in subgroups, presented as results of logistic regression models, adjusted for sociodemographic variables and presence of chronic diseases.

Results Prevalence of daily cigarette smoking was $26.0 \%$ for men in both years, and increased from $19.1 \%$ to $22.0 \%(p<0.001)$ in women from 2007 to 2014. Smoking prevalence increased especially in female patients with diabetes mellitus (from $9.9 \%$ to $16.4 \%, p=0.005$ ), obesity (from $17.1 \%$ to $21.6 \%, p=0.010$ ) and hypertension (from $11.2 \%$ to $14.2 \%, p=0.010$ ). Smoking prevalence increased significantly in unemployed men (from $43.6 \%$ to $57.1 \%$, $\mathrm{p}<0.001)$. In women, smoking prevalence increased in those aged $30-64$ years (from $21.9 \%$ to $26.3 \%, p<0.001$ ) and $65+$ (from $3.9 \%$ to $6.2 \%, p=0.002$ ), with primary (from $17.2 \%$ to $24.4 \%, p<0.001$ ) and secondary education (from $21.4 \%$ to $23.4 \%, p=0.021$ ), and with a European (from $16.6 \%$ to $26.1 \%, \mathrm{p}<0.001$ ) and non-European migration background (from $25.0 \%$ to $32.8 \%, p=0.003$ ). In the adjusted analysis for women in 2014, there was a higher likelihood of smoking (OR 1.22, 95\% Cl 1.12 to $1.32, p<0.001$ ) compared with 2007 , and for those affected by a chronic disease (OR $1.15,95 \% \mathrm{Cl} 1.06$ to $1.25, p=0.002$ ).

Conclusions There has been a remarkable increase in smoking prevalence over the 7-year period in women in Austria, especially for those with chronic diseases, higher age, lower education and a migration background. Better political and clinical efforts are needed to reduce the high tobacco use in Austria.

\section{INTRODUCTION}

Smoking is the most important and largest avoidable risk factor for ill health and premature mortality. ${ }^{1-3}$ Smoking also shortens life expectancy by approximately a decade. Risk
Strengths and limitations of this study

- The results are based on two cross-sectional surveys with representative sample sizes of more than 15000 subjects in each survey.

- The 7 years between the two surveys allowed us to analyse the trends in smoking prevalence over this time period, during which time most countries, in opposite to Austria, have made huge efforts in tobacco control.

- The surveys were population based, and thus allowed the analysis of healthy persons in parallel with patients with chronic diseases.

- Potential limitations can be ascribed to the fact that all the data are self-reported, and that there were slightly different methods applied in the two national surveys.

of death is about threefold higher in smokers compared with non-smokers. ${ }^{4}$ The biggest problems associated with smoking include cardiovascular diseases, cancers and respiratory problems. ${ }^{1}$

In industrialised countries, smoking peaked 10 years later in women compared with men but comparable consumption patterns are now seen in both sexes in most countries.

Between 2000 and 2013, risk of total mortality in women that smoke increased almost threefold paralleling the increase in men. There is also evidence of gender differences regarding the prevalence of smoking, and in the development of complications and temporal trends. In most countries, smoking prevalence is still higher in men, except in Sweden and Iceland. ${ }^{1}$

In many countries, smoking rates have decreased since 2000, by about $25 \%$ on average, with the most prominent decrease in Northern European countries. ${ }^{1}$ Analysis of data from 181 countries showed an average decline of smoking prevalence between 1980 and 2012 of $41.2 \%-31.1 \%$ in men and 
$10.6 \%-6.2 \%$ in women. Only a few countries, including Austria, increased their smoking prevalence, and Austrian women had the third highest absolute prevalence among the investigated countries. In conclusion, the authors urged that intensified efforts and policies were required in all countries to control tobacco use, especially in those with a high smoking prevalence. ${ }^{5}$

Advertising bans, restrictions in public spaces and restaurants, awareness campaigns and higher taxation are all antitobacco policies aimed at addressing the rise of smoking-related diseases. ${ }^{6}$ A failure to decrease smoking prevalence may be attributed to a lack of policies in one or more of these areas. Unfortunately, Austria is among the countries with poor smoking regulation policies. ${ }^{7}$ Since 2007, Austria has consistently had the lowest score in the Tobacco Control Scale of the Association of European Cancer Leagues, ${ }^{8}$ and does not fulfil its legal obligations under the WHO Framework Convention, which was ratified in 2005.910

According to the European Tobacco Control Report of the WHO European Region, since joining this network in 2005 , up to 2017 , Austria has had very high and stable scores in monitoring tobacco use, and in enforcing bans on tobacco advertising, promotion and sponsorship. Austria has also had high and stable scores in offering people to help quitting tobacco use and treating dependence (with free quit lines and medication for smoking cessation, for which, however, patients have to pay out of their own pocket). With regard to warnings on cigarette packages about the dangers of tobacco, and in raising tobacco taxes, Austria has also scored quite highly, and in both measures, scores increased between 2015 and 2017. Austria has, however, scored poorly in terms of warning people about the dangers of tobacco use through antitobacco campaigns. Only between 2015 and 2017 did Austria introduce national campaigns conducted with characteristics appropriate to WHO standards. The worst scores Austria received were in terms of protecting people from secondhand tobacco smoke. ${ }^{7}$ In fact, it was not until November 2019 that Austria introduced smoking bans in restaurants, cafés, and bars.

Against this background, it was the aim of this study to examine the prevalence of daily smoking and the relation to chronic diseases in men and women, and to monitor trends over time in Austria. In addition, we aimed to evaluate the prevalence of daily smoking in different subgroups, according to sociodemographic parameters and the occurrence of certain chronic diseases, and to assess if the association between these parameters with smoking status differed over time.

\section{METHODS}

\section{Datasets}

The databases used for the analysis were the two existing waves of the Austrian Health Interview Survey (AT-HIS) for $2007^{11}$ and $2014 .^{12}$ The AT-HIS is a representative population-based survey that is conducted at regular intervals in Austria, in subjects aged 15 years and older, carried out by Statistik Austria on behalf of the Austrian Ministry of Health. The questionnaires used for the AT-HIS were designed based on the European HIS (E-HIS), which is regularly conducted in the countries of the European Union (EU), ${ }^{13} 14$ and was adapted for Austria by an expert panel. For the AT-HIS, the sample is stratified into 32 geographical regions, with the same number of subjects in each region (there is a higher number for the three regions in Vienna). To balance the possible distortion brought about by the geographic stratification of the sample, the data have been weighted using the number of people living in each region, with the age in 5 years groups, and sex as the weighting factors in 2007, and geographical region, age, sex, family situation, migration background and education level as the weighting factors in 2014. Missing values have been imputed after fundamental analyses of the non-responses, based on sex, age, education and living region. There are, however, very few missing variables, and none in the case of the used variables regarding smoking. ${ }^{11} 12$

For the AT-HIS 2007, subjects were interviewed face to face using computer-assisted personal interviewing (CAPI) between March 2006 and March 2007 by 137 trained interviewers. The initial sample comprised 25130 addresses of the central population register, of which 621 addresses had to be excluded due to the fact that the target person had moved, had already died or the address did not exist anymore. The remaining 24509 persons were the gross sample size, which was the basis for calculating the response rate. Of this total, 9656 subjects were excluded for different reasons: 5709 subjects refused or terminated the interview; 3308 were excluded due to difficulties in contacting them or because of deficiency regarding their command of the German language; and 639 cases were excluded due to unsatisfactory data quality. The data of a total of 15474 subjects were eligible for analysis, representing a response rate of $63.1 \%$. The AT-HIS 2014 was carried out from October 2013 to June 2015 via computer-assisted telephone interviewing (CATI). The survey comprised a gross sample size of 38768 subjects from the central population register. Of this total, 21343 subjects initially refused to participate; another 1594 subjects who initially declared their interest to participate could no longer be reached, or refused the telephone interview; 25 subjects terminated the interview; and 35 subjects were excluded due to unsatisfactory data quality. Thus, a net sample of 15771 subjects was included in the survey, yielding a response rate of $40.7 \%$. The flow chart for the recruitment processes in both surveys is depicted in figure 1 . To increase the response rate, subjects were repeatedly reminded and given a gift voucher as incentive.

\section{Variables}

Daily cigarette smoking was indicated in the AT-HIS 2007 if subjects answered 'yes' to the question 'Have you smoked yet in your life more than 100 cigarettes, cigars, pipes or other tobacco products?', answered 'yes daily' to the 


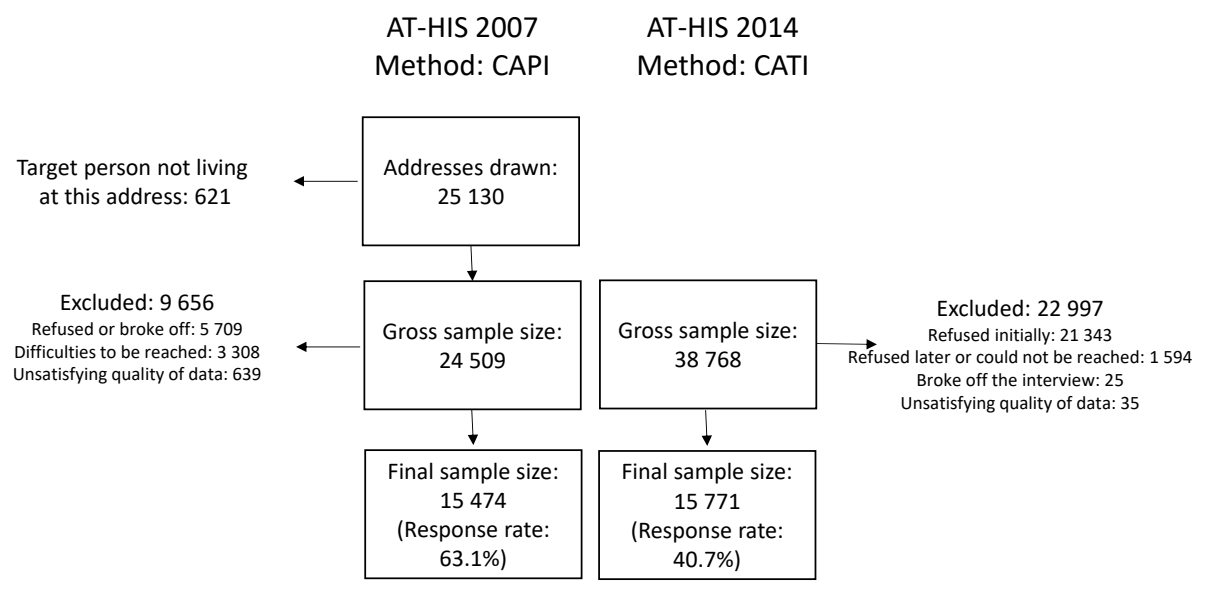

Figure 1 Flow chart of the recruitment processes in the two health interview surveys

question 'Do you smoke currently?', and answered with 'Cigarettes from cigarette boxes' to the question 'Which of the following tobacco products do you smoke daily?'. Daily cigarette smoking was indicated in the AT-HIS 2014, if subjects answered 'yes, daily' to the question 'Do you smoke?' and 'Cigarettes' to the question 'Which of the following tobacco products do you use most frequently?' Furthermore, in the 2014 survey, the number of cigarettes smoked per day and the age of starting smoking were recorded for those who indicated that they smoked cigarettes daily.

For the sociodemographic variables, age was recorded in three categories: 15-29 years, 30-64 years and 65 years and older. Highest education level was categorised as primary education (school until the age of 15 years), secondary education (education up to the Austrian school leaving exam 'Matura' at the age of 18 or 19 years, or apprenticeship), and tertiary education (university or university of applied sciences, or further vocational education after the 'Matura'). Employment status was recorded in three categories as gainfully employed (including self-employed), unemployed or not gainfully employed (retirement, in formal education, housewives and househusbands, subjects in maternity or paternity leave, and persons in military service). Land of birth was recorded in three categories: Austria, EU and non-EU. In the 2007 survey, the land of birth variable of EU states comprised the 27 states in the EU for the year 2006, except Austria, as well as the four states of the European Free Trade Association. In the 2014 survey, the land of birth variable of EU states comprised the 28 European states in the EU for the year 2014, except Austria. Urbanisation was recorded as living in the Austrian capital Vienna (the only Austrian city with a population approaching two million inhabitants) or in any other Austrian federal state (in which no city has more than 300000 inhabitants). Family status was recorded with two categories of in a relationship or not in a relationship, with in a relationship also including being married. Being affected by at least one chronic disease was recorded with the question 'Do you have a chronic health problem?' Furthermore, the specific chronic diseases were recorded and the participants were asked if they had been affected by the respective chronic health problem within the last 12 months. For this analysis, the following chronic health problems were considered: diabetes mellitus, hypertension, chronic obstructive pulmonary disease, stroke and myocardial infarction. In addition, body mass index (BMI) was calculated as $\mathrm{kg} / \mathrm{m}^{2}$ from self-reported data on body weight and body height, and a BMI $\geq 30 \mathrm{~kg} / \mathrm{m}^{2}$ was classified as obese.

\section{Statistical analyses}

IBM SPSS V.24 was used for the statistical analyses. All the analyses were carried out with the weighted data, as described in the dataset description. Bivariate analyses were undertaken by means of cross-tabulations, and group differences were assessed with Pearson's $\chi^{2}$ tests. To test for the interaction between the year of evaluation and sociodemographic factors or health factors on the likelihood of daily smoking, we performed binary logistic regression analyses. The reason for testing the interaction was that, if there a significant interaction was found, we could assume that there was a difference in the association between the respective tested factors with daily smoking in the respective year. If we found a significant interaction, we demonstrated the prevalence of daily 
smoking in the respective subgroup, stratified by the year of the survey. Daily cigarette smoking was defined as the dependent variable, and all the socio-demographic and health factors were defined as the independent variables. In addition, the product between the year of evaluation with the respective sociodemographic or health factor was also defined as an independent variable. For every possible interaction, a separate regression analysis was conducted, adjusted for all the other mentioned variables. The $\mathrm{p}$ value for this product in the fully adjusted model was considered as an indicator of whether there was a significant interaction effect on smoking status or not. The estimates of the logistic regression models with all the mutually adjusted sociodemographic and health variables on the likelihood of daily smoking are presented as OR and $95 \% \mathrm{CI}$.

\section{Patient and public involvement}

There was no patient involvement in this study.

\section{RESULTS}

\section{Prevalence of daily smoking}

Prevalence of daily cigarette smoking in Austria was 26.0\% in men in both, 2007 and 2014. In women, there was a significant increase in smoking prevalence from $19.1 \%$ in 2007 to $22.0 \%$ in 2014 ( $\mathrm{p}<0.001)$. In the 2014 survey, men reported a mean age of starting smoking of 17.7 (SD: 4.8) years, and women reported a mean age of 18.8 (SD: 6.2) years $(p<0.001)$. The mean number of cigarettes smoked per day was reported in the 2014 survey as 17.3 (SD: 9.2) for men, and 13.6 (SD: 6.8) for women $(\mathrm{p}<0.001)$.

\section{Sample characteristics}

As shown in table 1 , for men, there were significant differences in age group categories (higher age in 2014), education level (higher education in 2014), employment status (fewer gainfully employed in 2014) and land of birth (more migrants from the EU and fewer from non-EU countries in 2014), and a higher prevalence of obesity, hypertension and myocardial infarction in 2014 compared with 2007. In women, there were significant differences in education level (higher education in 2014), employment status (more gainfully employed, more unemployed, but fewer not gainfully employed in 2014) and land of birth (more migrants from the EU and fewer from non-EU countries in 2014), and a lower prevalence of diabetes mellitus, but a higher prevalence of hypertension, and myocardial infarction in 2014 compared with 2007.

\section{Prevalence and trends of daily smoking in various subgroups}

According to table 2, for men, the prevalence of smoking was particularly high in people aged 15-29 years, in those with no tertiary education, in the unemployed, in those living in Vienna, in those not in a relationship, and in subjects with no chronic disease. For men, there was a significant interaction between the year of evaluation and the employment status on the likelihood of daily cigarette smoking. In 2014, unemployed men smoked even more than unemployed men in 2007. According to table 3 , in women, the prevalence of smoking was particularly high in the 15-29 age group, as well as in those aged 30-64 years, in those with primary and secondary education, in the unemployed, in those with a migration background (especially from non-EU countries), in those from Vienna in the year 2014 (which was not the case in 2007), in those not in a relationship in 2014 (again, not the case in 2007), and in those with no chronic disease in 2007 (not in 2014). For women, there was a significant interaction between the year of evaluation with the following three parameters on the likelihood of daily cigarette smoking: age, education level and land of birth. Compared with 2007, in 2014, the proportion of women who smoked was higher in the older age groups (30-64, and particularly $65+$ years), but almost equal in younger women. Compared with 2007, in 2014, women with a lower education level smoked more, and those with a higher education level smoked less often. Furthermore, compared with 2007, the increase in smoking prevalence in women with a migration background was much higher than the increase in women born in Austria.

\section{Smoking prevalence and chronic diseases}

The smoking prevalence in men and women with certain health conditions is presented in table 4. Compared with the general population, the smoking prevalence in patients with chronic diseases was lower, except for men and women with COPD (2007 and 2014), and in women after myocardial infarction (2007). In men with chronic diseases, there was no significant difference in smoking prevalence in the years 2014 and 2007. In women, however, in 2014, there was a significantly higher smoking prevalence in those with any chronic disease, in those with diabetes mellitus, in those with obesity, and in those with hypertension, compared with 2007.

\section{Factors associated with daily smoking: multivariate analysis}

Table 5 shows the association between the year of evaluation, the sociodemographic variables and the health status with the likelihood of daily cigarette smoking in men and women. From this multivariate analysis, it can be seen that women had a $22 \%$ higher likelihood of smoking in 2014 compared with 2007. In addition, women had a $15 \%$ higher likelihood of daily smoking when affected by chronic diseases compared with women without chronic diseases. Sociodemographic variables were significantly associated with the odds of daily smoking in both sexes, in the multivariate analysis.

\section{DISCUSSION}

\section{Main findings in comparison to other countries}

In this survey of the trends in smoking in the Austrian population over 7 years, we found that the prevalence of daily smoking increased in women from $19.1 \%$ in 2007 
Table 1 Characteristics and change of characteristics in the male and female participants

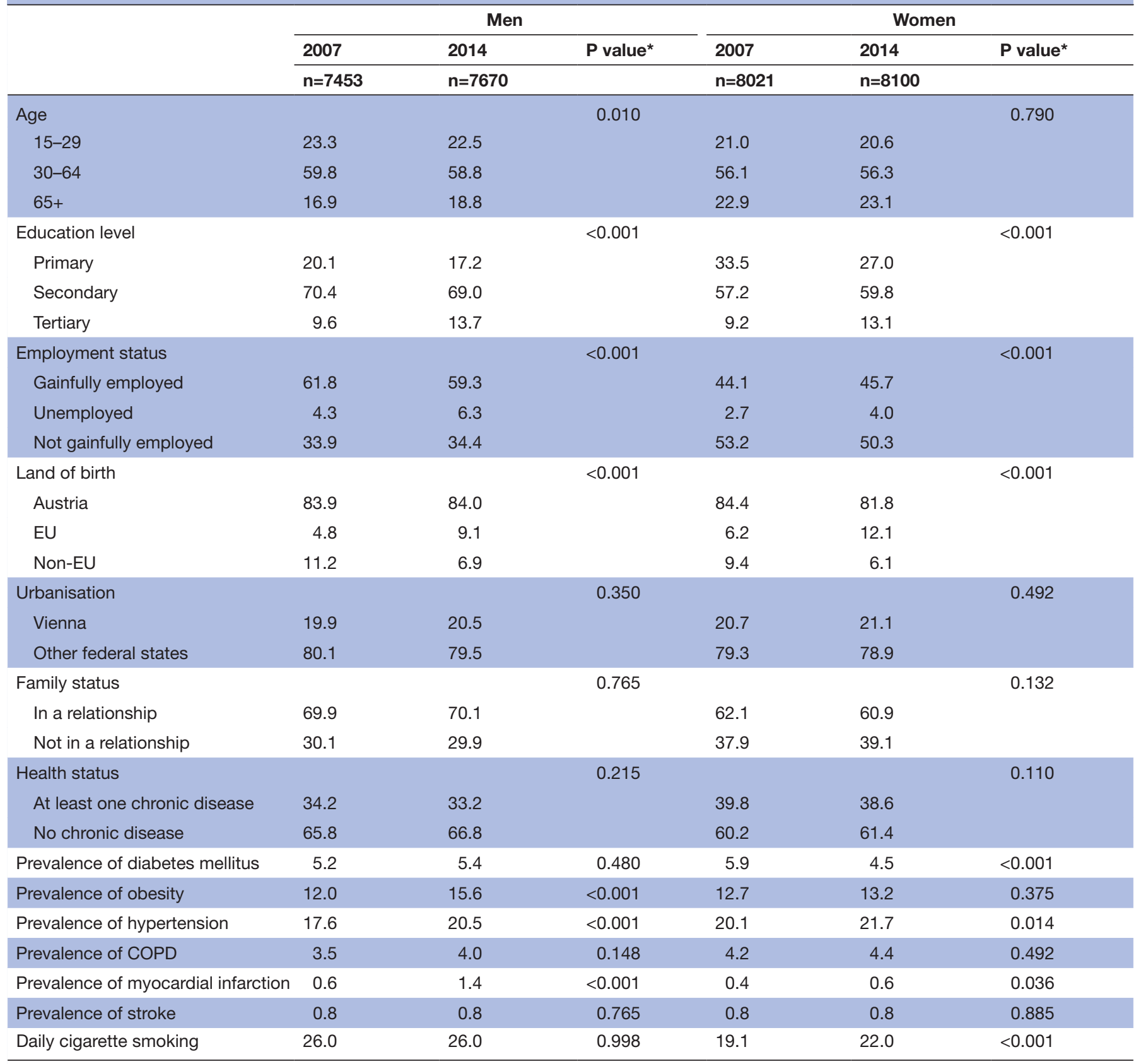

${ }^{*} P$ value as results of the $\chi^{2}$ test between 2007 and 2014 .

COPD, chronic obstructive pulmonary disease; EU, European Union.

to $22 \%$ in 2014 , while it remained steadily high over time in men at $26.0 \%$, indicating a small gender gap in Austria. These findings are in line with Austrian sales data that show stable numbers of sold cigarettes at 4.3-5 cigarettes per person per day, but clearly increasing levels for tobacco for roll-your-own cigarettes, pipes, chewing tobacco and other tobacco products between the years 2009 and 2014. In addition, sales data point towards equalisation of sales habits between men and women. ${ }^{15}$ The female level recorded in our analysis corresponds to one of the highest figures worldwide, with only Greece and Bulgaria having a higher prevalence of smoking in women. ${ }^{5}$ As in all Organisation for Economic Co-operation and Development (OECD) countries, except for Sweden and Iceland, ${ }^{1}$ smoking prevalence in Austria is higher in males than females. Furthermore, $56 \%$ of the countries in the OECD had less than $20 \%$ of their adult population smoking daily in 2013. ${ }^{1}$ Thus, smoking in Austria deserves special attention. In fact, cardiovascular mortality in Austria, as an example of the consequences of a high smoking prevalence, has not decreased over the last decades by as much as other comparable countries. Since smoking prevalence in these countries decreased, showing an opposite trend to Austria, smoking has been 
Table 2 Prevalence of smoking in the male subpopulations in 2007 and 2014

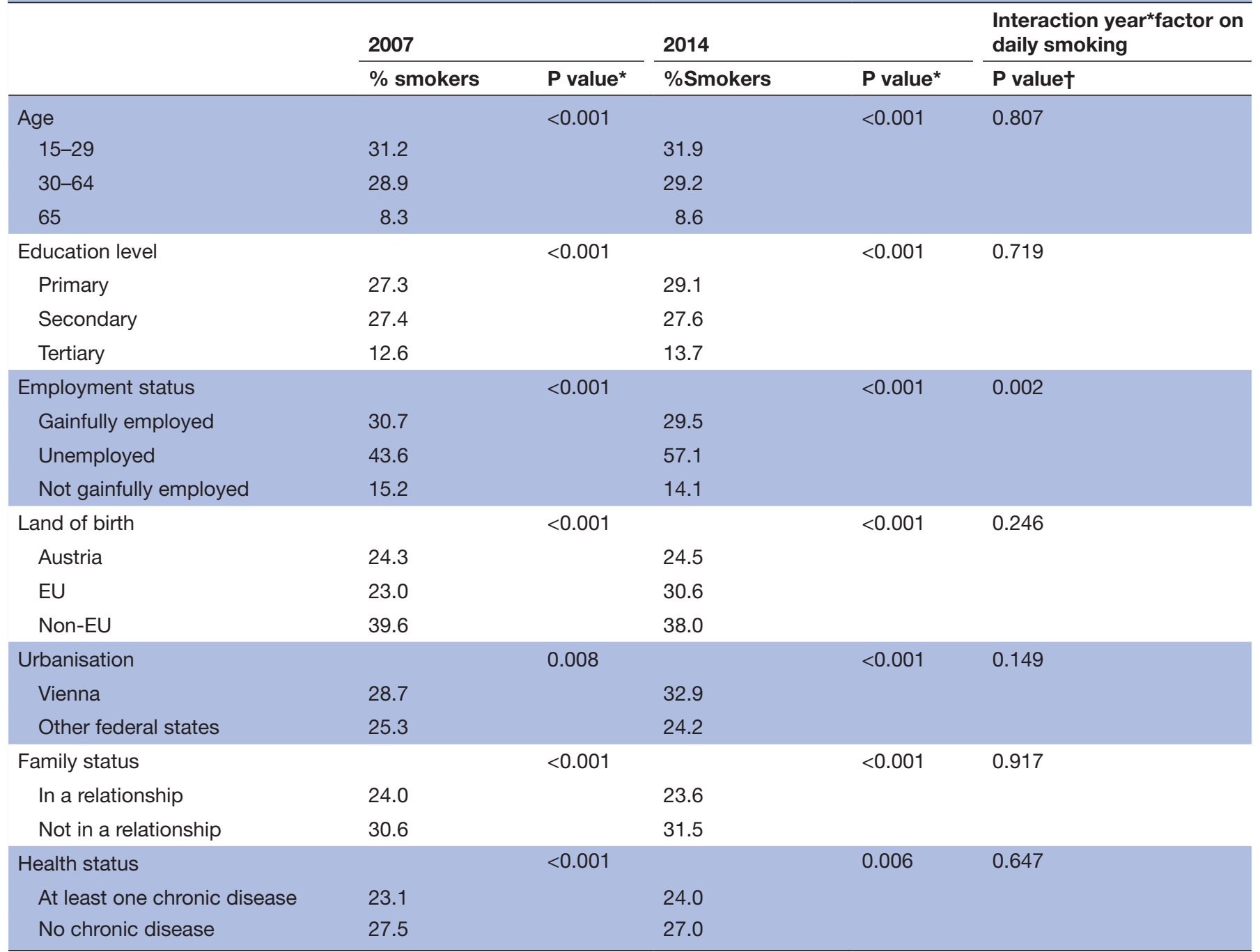

${ }^{*} \mathrm{P}$ value as results of the $\chi^{2}$ test: differences in smoking prevalence based on sociodemographic and health variables in the respective surveys, 2007 and 2014.

†P value as results of the binary logistic regression analyses for the interaction between year of evaluation and the respective sociodemographic or health variable on the likelihood of daily smoking (dependent variable), adjusted for all sociodemographic and health variables and the year of evaluation.

EU, European Union.

discussed as a responsible factor for these different developments. ${ }^{16}$

\section{Smoking prevalence in different subgroups}

Comparing daily smokers in the different subgroups of men indicates the highest prevalence at a young age, in migrants, in those with a low education level, in the unemployed, those living in Vienna, in those of a single status and in those without a chronic disease. On the other hand, in women, the prevalence of daily smoking was relatively high for the young and middle aged, for those with low as well as higher levels of education, for the unemployed, as well as migrants, especially those from non-EU countries. In 2014 only, there was a high prevalence of smoking in women with a single status, in those living in Vienna and in those with chronic diseases. We also found an increase in the smoking rates in women in those of a higher age, in those with a lower education level, and in those with an origin of non-EU countries in 2014, compared with 2007. In men, however, smoking prevalence in the subgroups did not substantially change, except that smoking was more common in unemployed men in 2014, compared with 2007. These subgroups with a relatively high smoking prevalence should be regarded as important target groups for smoking cessation and smoking prevention programmes.

Between the two surveys, there were changes in the population, which can be seen in table 1 . These changes might have contributed to the changes in smoking prevalence. In particular, the Austrian population became older between 2007 and 2014, and there was a higher proportion of people with a higher education level, which should have resulted in a lower total prevalence 
Table 3 Prevalence of smoking in the female subpopulations in 2007 and 2014

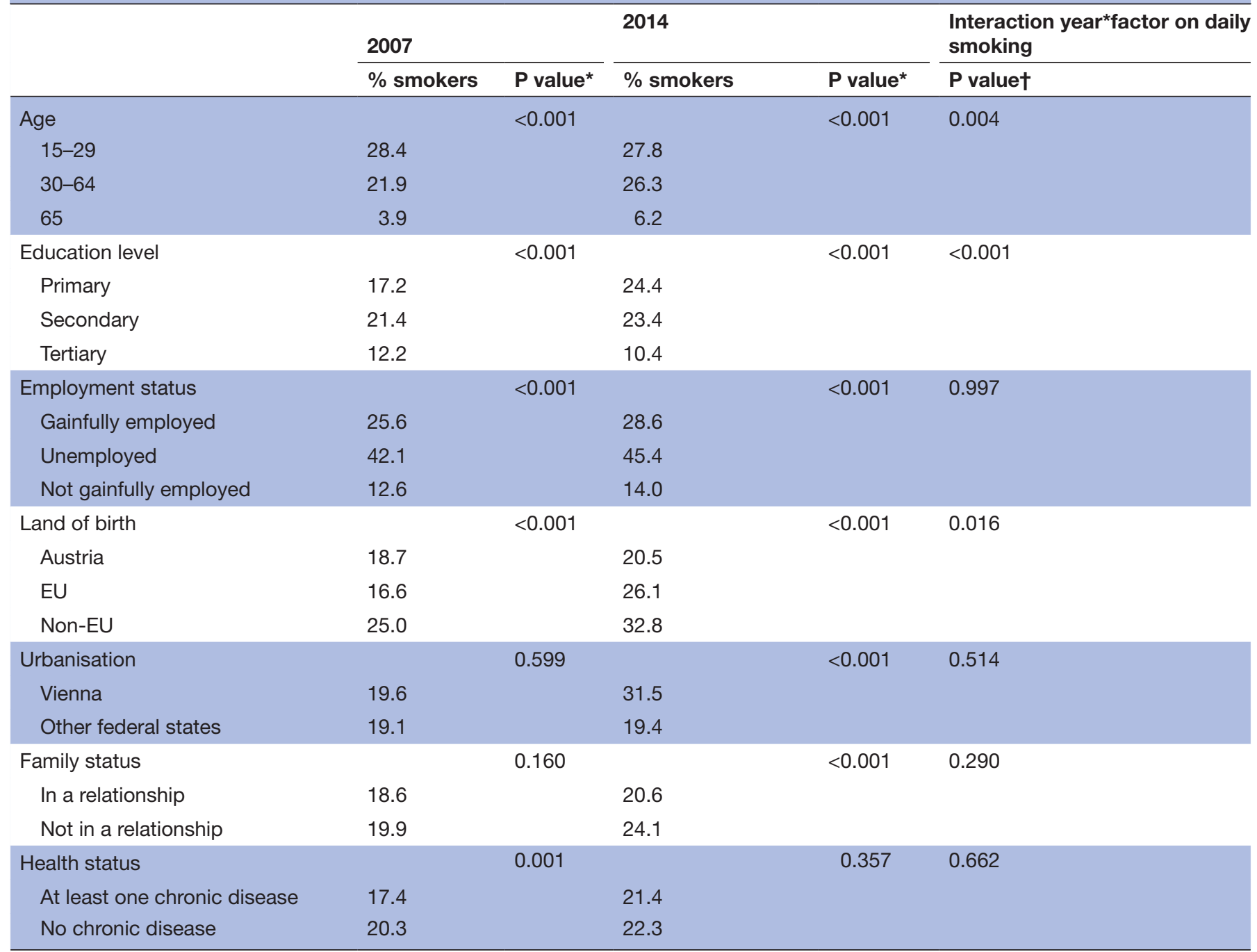

${ }^{*} \mathrm{P}$ value as results of the $\chi^{2}$ test: differences in smoking prevalence based on sociodemographic and health variables in the respective surveys, 2007 and 2014.

$\dagger P$ value as results of the binary logistic regression analyses for the interaction between year of evaluation and the respective sociodemographic or health variable on the likelihood of daily smoking (dependent variable), adjusted for all sociodemographic and health variables and the year of evaluation.

EU, European Union.

of smoking, because, as we also could see in our results, people with a higher education level and older persons generally smoke less. However, we also saw an increase in smoking prevalence in middle-aged and older women, and in women with secondary education. Furthermore, there was an increase in migrants from other European countries and an increase of smoking prevalence in female migrants from EU and non-EU countries. The combination of these factors could have contributed to the increase in total smoking prevalence in women.

\section{Smoking and chronic diseases}

Smoking is an avoidable risk factor for many chronic diseases, in particular cardiovascular disease, various cancers and respiratory diseases, but also metabolic diseases such as diabetes mellitus. Smoking also causes adverse outcomes in these diseases, such as complications, acute and unstable episodes, comorbidity, a higher mortality and a worse quality of life. Therefore, we also evaluated in particular the proportion of daily cigarette smokers in both sexes in subjects with chronic diseases, and the changes over time. Due to the cross-sectional nature of the study, we cannot conclude if smoking contributed to the genesis of the respective chronic diseases. However, since smoking cessation is part of the recommended therapy and guidelines in many chronic diseases, including diabetes mellitus, ${ }^{17} 18$ cardiovascular disease $^{19}$ and $\mathrm{COPD},{ }^{20}$ a high smoking prevalence in these patients can be interpreted as smoking cessation not being very successful, or smoking cessation not being given a high priority in chronic disease therapy. Since we found higher increases in smoking prevalence in women with chronic diseases compared with men, we can assume 
Table 4 Proportion of daily cigarette smokers in men and women of the different populations and changes over time

\begin{tabular}{|c|c|c|c|c|c|c|c|c|}
\hline & \multicolumn{4}{|c|}{ Men } & \multicolumn{4}{|c|}{ Women } \\
\hline & 2007 & 2014 & Change, \% & P value* & 2007 & 2014 & Change, \% & P value* \\
\hline General population & 26 & 26 & \pm 0 & 0.998 & 19.1 & 22 & 15.00 & $<0.001$ \\
\hline Diabetes mellitus & 14.5 & 17.7 & 22.00 & 0.219 & 9.9 & 16.4 & 67.00 & 0.005 \\
\hline Obesity (BMI $\left.\geq 30 \mathrm{~kg} / \mathrm{m}^{2}\right)$ & 23.2 & 24.7 & 6.00 & 0.405 & 17.1 & 21.6 & 26.00 & 0.01 \\
\hline Myocardial infarction & 8.9 & 20 & 125.00 & 0.094 & 20 & 14.3 & -29.00 & 0.506 \\
\hline Stroke & 10.2 & 17.5 & 72.00 & 0.245 & 9.1 & 20 & 120.00 & 0.076 \\
\hline
\end{tabular}

${ }^{*} \mathrm{P}$ value as results of $\chi^{2}$ test between 2007 and 2014 .

$\mathrm{BMI}$, body mass index; COPD, chronic obstructive pulmonary disease.

that treatment according to guidelines, which includes smoking cessation, has worsened, particularly in women. Less often treating according to guidelines, in women compared with men has also been reported in other studies. ${ }^{21} 22$

The largest and most worrisome increase in smoking of $67 \%$ was found in women with diabetes mellitus. This is of particular concern as women with diabetes mellitus are already a very high risk population, especially for myocardial infarction and stroke, with a greater relative risk than diabetic men. ${ }^{23}{ }^{24}$ Furthermore, smoking is a prominent risk factor for both development of insulin resistance and diabetes mellitus, as well as for the progression of diabetic complications. Data from the Third National Health and Nutrition Examination Survey showed that tobacco smoke exposure is related to the metabolic syndrome in adolescents. ${ }^{25}$ Another recent meta-analysis showed a pooled adjusted relative risk of $55 \%$ for total mortality and $49 \%$ for cardiovascular mortality associated with smoking in patients with diabetes mellitus. ${ }^{26}$

A special concern is the high number of women of reproductive age that smoke. Although we do not know if these women smoked during their potential pregnancies, we can assume that at least some of them did. Smoking during pregnancy exposes the fetus to a high risk of health problems in utero and in later life, further contributing to the transgenerational programming of cardiometabolic risk. ${ }^{27} 28$

The high prevalence of smoking in patients with myocardial infarction or stroke in Austria is also alarming. According to an 8-year follow-up study in those suffering acute myocardial infarction, smokers lost 10.3 years of life due to premature death compared with 5.4 years for non-smokers. More years of life were lost among women that smoke than among men that smoke. ${ }^{29}$ In addition to the causal links of smoking to many chronic diseases, continued smoking also contributes to exacerbations of these chronic conditions. Thus, it is of the utmost importance to support these patients to become tobacco free. Special support may be necessary as the stress related with chronic diseases may aggravate withdrawal symptoms in these patients.

It can, therefore, be expected that especially vulnerable groups with chronic diseases, metabolic disorders, lower socioeconomic status, migrants and females in general, which also often suffer from additional mental health problems, are particularly at risk of the sequelae of smoking and of the lower success of cessation programmes. However, some studies have reported success of smoking cessation programmes in patients with acute and chronic diseases who might be particularly motivated to quit. ${ }^{4}$ Either way, greater potential harm from continued use can be expected in patients with chronic diseases. Such studies have highlighted the importance of intensive guidance and advice to help quit smoking in patients treated in hospital for diseases related to smoking and after discharge. ${ }^{30}$

\section{Policy implications}

Austria is notorious for its tardiness in introducing policies to reduce the harm associated with tobacco use, ${ }^{8}$ especially when compared with other countries in the European WHO region. ${ }^{7}$ Therefore, the existing high prevalence of smoking is no surprise. There was no improvement in the Austrian tobacco policies after Austria ratified the European WHO Framework Convention on Tobacco Control in the year 2005, up until the year $2015 .^{7}$ This suggests that the lack of enhancement in tobacco policies during the period between our two surveys resulted in an increase of the smoking prevalence in women, and a lack of a decrease of the smoking prevalence in men. Only in the years after the second survey did Austria make some improvements in tobacco policies, that is, more prominent warnings on cigarette packages, higher tobacco taxes between 2015 and $2017,{ }^{7}$ and the introduction of a total smoking ban in bars and restaurants in 2019. It will be interesting to see if these measures will result in changes in smoking prevalence in future HIS. Nevertheless, there is still a need to improve the policies offering people help in smoking cessation, from 
Table 5 Association of sociodemographic and health variables on the likelihood of daily cigarette smoking

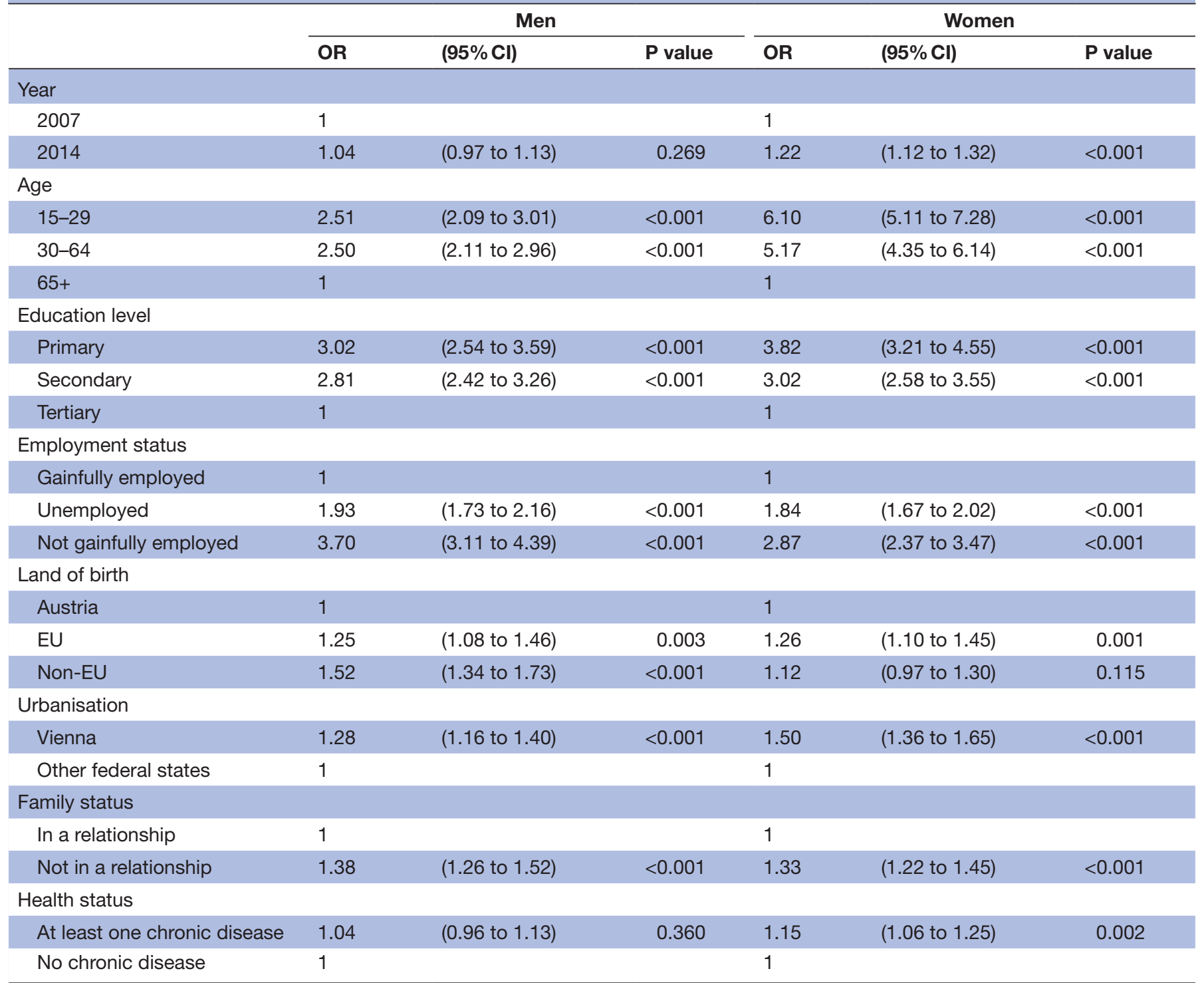

Results of multivariate logistic regression model based on both surveys in 2007 and 2014; each included variable is mutually adjusted for all the other variables.

EU, European Union.

which patients with chronic diseases will especially profit, and our results clearly show the need for this.

\section{Strengths and limitations}

The strengths of this study include the high sample size with more than 15000 subjects in each survey, and the population-based design, allowing us to analyse healthy subjects in parallel with subjects with clinical conditions. Statistik Austria is the only organisation in Austria with access to the central population register, which allows them to draw samples from the universal population. Weighting the sample according to the age, sex, and geographical region (and additional socio-demographic variables for the 2014 survey) of the general population can yield representative samples. The fact that the trends of the self-reported smoking in our analysis are reflected in the sales data of tobacco products ${ }^{15}$ also suggests that our findings are valid. A potential limitation is that all the factors analysed were self-reported. This might have led to underestimation of the smoking prevalence, as well as underestimation of the prevalence of chronic diseases. However, another Austrian study has shown that self-reported data on smoking are highly valid when compared with objectively verified data on smoking, for example, exhaled carbon monoxide. ${ }^{31}$ This might be due to the fact that, in Austria, compared with other countries, smoking and reporting of such is not associated with social stigma, as a result of the lack of smoking regulation policies. Although the total sample size in our study was large, the sample sizes in the subgroups (eg, women with diabetes mellitus who smoke) were relatively 
small, yielding a limited power for the statistical analyses in the subgroups. A further limitation is the fact that the methods applied in the two AT-HIS surveys differed, that is, CAPI in 2007 and CATI in 2014, with subsequent different response rates, slightly different weighting factors, and minor differences in the wording regarding smoking habits, which limits the possibility of comparing the two surveys. In addition, the different response rates $(63.1 \%$ vs $40.7 \%)$ have to be taken into account. These differences reflect the different survey methods, where personal interviewing led to a higher response rate and telephone interviewing to a lower response rate. For Austrian surveys, a response rate of $40 \%$ for a nonmandatory survey is regarded as expected and a response rate of more than $60 \%$ as relatively high. ${ }^{11}{ }^{12}$ Furthermore, it could be hypothesised that answers obtained with CATI or CAPI would differ, and that a face-to-face interview could yield more honest answers, compared with telephone interviewing, thus leading to higher prevalence rates of smoking. However, a study conducted in Bavaria, the German federal state next to Austria, compared the validity of a population-based CATI survey with the German National Health Examination Survey, a survey with face-to-face contact to the examiners. In this study, smoking prevalence obtained with CATI was indeed non-significantly slightly higher in the face-to-face survey compared with CATI (29.0 vs $30.1 \%) .^{32}$ Similarly, in a Norwegian study, although with small sample sizes, there was no significant difference in smoking status when obtained with either CATI or CAPI, with a nonsignificantly higher smoking prevalence obtained with CAPI (31 vs $39 \%) .{ }^{33}$ If under-reporting of smoking would be a higher problem in CATI than in CAPI, this would have led to an underestimation of the increased smoking prevalence in women found in our survey and to an actual increase in smoking status in men. When adding the $4 \%$ higher rates in CAPI derived from the Bavarian study, the prevalence of smoking in Austria would have increased from $26.0 \%$ to $27.0 \%$ in men and from $19.1 \%$ to $22.9 \%$ in women. And when adding the $26 \%$ higher rates in CAPI derived from the Norwegian study, the prevalence of smoking in Austria would have increased from 26.0\% to $32.8 \%$ in men and from $19.1 \%$ to $27.7 \%$ in women. Therefore, the trends in smoking prevalence rates in our survey represent conservative estimates.

\section{CONCLUSIONS}

In summary, better tobacco control and regulatory implications, as well as greater public health and clinical efforts, are urgently needed to address and reduce the high tobacco use and exposure to secondhand smoke in Austria. Examples of such policies to reduce smoking prevalence include creating smoke-free spaces, raising taxes and educating people about the dangers of smoking. This is of particular importance in the most vulnerable patients coping with chronic conditions and continued smoking. Intensified tobacco control efforts are needed in countries such as Austria where the percentage of smokers is consistently high in men or even increasing in women. Inclusion of a female perspective in smoking prevention and cessation policies appears crucial to buck the current trend and to protect the most vulnerable group of young women. Such policies could contribute to a better health-related quality of life for the population, and to cost reductions in the healthcare system.

Acknowledgements We would like to thank Statistik Austria for providing the data-sets and for the help in answering the reviewers' requests. We also want to thank the four reviewers for their valuable comments. Furthermore, we want to thank Mark Ackerley for proofreading the paper.

Contributors TED, HB and AK-W designed the manuscript and the analyses jointly. TED conducted the statistical analyses. TED and AK-W drafted different parts of the manuscript. All authors have commented on the manuscript draft and read and approved the final version of the manuscript.

Funding The authors have not declared a specific grant for this research from any funding agency in the public, commercial or not-for-profit sectors.

Competing interests None declared.

Patient and public involvement Patients and/or the public were not involved in the design, or conduct, or reporting, or dissemination plans of this research.

Patient consent for publication Not required.

Ethics approval The secondary analysis of the AT-HIS databases which were used for this study was approved by the Ethics Committee of the Medical University Vienna: (EK \# 770/2011 for the AT-HIS 2007 and EK \# 2211/2015 for the AT-HIS 2014).

Provenance and peer review Not commissioned; externally peer reviewed.

Data availability statement Data may be obtained from a third party and are not publicly available. Data can be obtained on request at Statistik Austria.

Open access This is an open access article distributed in accordance with the Creative Commons Attribution Non Commercial (CC BY-NC 4.0) license, which permits others to distribute, remix, adapt, build upon this work non-commercially, and license their derivative works on different terms, provided the original work is properly cited, appropriate credit is given, any changes made indicated, and the use is non-commercial. See: http://creativecommons.org/licenses/by-nc/4.0/.

\section{ORCID iDs}

Thomas Ernst Dorner http://orcid.org/0000-0002-5218-1160

Alexandra Kautzky-Willer http://orcid.org/0000-0002-3520-4105

\section{REFERENCES}

1 Smoking O, Factbook O. Economic, environmental and social statistics 2015-2016. Paris: OECD Publishing, 2016: 208-9.

2 Jha P, Ramasundarahettige C, Landsman V, et al. 21St-Century hazards of smoking and benefits of cessation in the United States. $N$ Engl J Med 2013;368:341-50.

3 Thun MJ, Carter BD, Feskanich D, et al. 50-Year trends in smoking-related mortality in the United States. $N$ Engl J Med 2013;368:351-64

4 Cully M. Public health: the benefits and challenges of smoking cessation. Nat Rev Cardiol 2013;10:117.

$5 \mathrm{Ng} \mathrm{M}$, Freeman MK, Fleming TD, et al. Smoking prevalence and cigarette consumption in 187 countries, 1980-2012. JAMA 2014;311:183-92.

6 Bala MM, Strzeszynski L, Topor-Madry R, et al. Mass media interventions for smoking cessation in adults. Cochrane Database Syst Rev 2013;6:CD004704.

7 WHO Regional Office for Europe. Tacking stock: tobacco control in the WHO European region in 2017. Copenhagen: WHO Regional Office for Europe, 2017.

8 Neuberger M. Austria's new government: a victory for the tobacco industry and public health disaster? : Blog - Tobacco Control, 2018. Available: https://blogs.bmj.com/tc/2018/01/09/austrias-newgovernment-a-victory-for-the-tobacco-industry-and-public-healthdisaster/ [Accessed 9 Jan 2018]. 
9 Hefler M. Worldwide news and Comment. Tob Control 2018;27:246-9.

10 Burki TK. Austrian MPS vote against smoking ban. Lancet Oncol 2018;19:e234.

11 Klimont J, Kytir J, Leitner B, et al. Statistik Austria im Auftrag vom Bundesministerium für Gesundheit, Familie und Jugend und der Bundesagentur. In: Österreichische Gesundheitsbefragung 2006/07. Hauptergebnisse und methodische Dokumentation. Wien, 2007.

12 Klimont J, Baldaszti E. Österreichische Gesundheitsbefragung 2014. Hauptergebnisse des Austrian health interview survey (ATHIS) und methodische Dokumentation. Wien: Statistik Austria im Auftrag vom Bundesministerium für Gesundheit und der Bundesagentur, 2015.

13 Aromaa A, Koponen P, Tafforeau J, et al. Evaluation of health interview surveys and health examination surveys in the European Union. Eur J Public Health 2003;13:67-72.

14 Eurostat. European health interview survey. Available: http://ec. europa.eu/eurostat/web/microdata/european-health-interview-survey [Accessed 4 Jan 2018].

15 Schmutterer I. Tabak- und verwandte Erzeugnisse: Zahlen und Fakten. Vienna: Gesundheit Österreich, 2019.

16 Grabovac I, Hochfellner L, Rieger M, et al. Impact of Austria's 2009 trans fatty acids regulation on all-cause, cardiovascular and coronary heart disease mortality. Eur J Public Health 2018;28:4-9.

17 American Diabetes Association. 4. Lifestyle Management: Standards of Medical Care in Diabetes-2018. Diabetes Care 2018;41:S38-50.

18 Brath H, Kaser S, Tatschl C, et al. [Smoking, alcohol and diabetes (Update 2019)]. Wien Klin Wochenschr 2019;131:67-70.

19 Fihn SD, Gardin JM, Abrams J, et al. 2012 ACCF/AHA/ACP/AATS/ PCNA/SCAI/STS guideline for the diagnosis and management of patients with stable ischemic heart disease: a report of the American College of cardiology Foundation/American heart association Task force on practice guidelines, and the American College of physicians, American association for thoracic surgery, preventive cardiovascular nurses association, Society for cardiovascular angiography and interventions, and society of thoracic surgeons. Circulation 2012;126:e354-471.

20 Vogelmeier CF, Criner GJ, Martinez FJ, et al. Global strategy for the diagnosis, management, and prevention of chronic obstructive lung disease 2017 report: gold executive summary. Eur Respir J 2017;49:1700214.

21 Fodor JG, Tzerovska R, Dorner T, et al. Do we diagnose and treat coronary heart disease differently in men and women? Wien Med Wochenschr 2004;154:423-5.

22 Rossi MC, Cristofaro MR, Gentile S, et al. Sex disparities in the quality of diabetes care: biological and cultural factors may play a different role for different outcomes: a cross-sectional observational study from the AMD Annals initiative. Diabetes Care 2013;36:3162-8.

23 Peters SAE, Huxley RR, Woodward M. Diabetes as risk factor for incident coronary heart disease in women compared with men: a systematic review and meta-analysis of 64 cohorts including 858,507 individuals and 28,203 coronary events. Diabetologia 2014;57:1542-51.

24 Peters SAE, Huxley RR, Woodward M. Diabetes as a risk factor for stroke in women compared with men: a systematic review and metaanalysis of 64 cohorts, including 775385 individuals and 12539 strokes. Lancet 2014;383:1973-80.

25 Weitzman M, Cook S, Auinger P, et al. Tobacco smoke exposure is associated with the metabolic syndrome in adolescents. Circulation 2005;112:862-9.

26 Pan A, Wang Y, Talaei M, et al. Relation of smoking with total mortality and cardiovascular events among patients with diabetes mellitus: a meta-analysis and systematic review. Circulation 2015;132:1795-804.

27 Meyer KF, Verkaik-Schakel RN, Timens W, et al. The fetal programming effect of prenatal smoking on Igf1r and Igf1 methylation is organ- and sex-specific. Epigenetics 2017;12:1076-91.

28 Banderali G, Martelli A, Landi M, et al. Short and long term health effects of parental tobacco smoking during pregnancy and lactation: a descriptive review. J Trans/ Med 2015;13:327.

29 Grundtvig M, Hagen TP, Amrud ES, et al. Reduced life expectancy after an incident hospital diagnosis of acute myocardial infarction--effects of smoking in women and men. Int $J$ Cardiol 2013;167:2792-7.

30 Rigotti NA, Clair C, Munafò MR, et al. Interventions for smoking cessation in hospitalised patients. Cochrane Database Syst Rev 2012;5:CD001837.

31 Brath H, Grabovac I, Schalk H, et al. Prevalence and correlates of smoking and readiness to quit smoking in people living with HIV in Austria and Germany. PLoS One 2016;11:e0150553.

32 Meyer N, Fischer R, Weitkunat R, et al. [Evalutation of health monitoring in Bavaria by computer-assisted telephone interviews (CATI) in comparison to the German National Health Examination Survey conducted in 1998 by the Robert Koch Institute]. Gesundheitswesen 2002;64:329-36.

33 Brustad M, Skeie G, Braaten T, et al. Comparison of telephone vs face-to-face interviews in the assessment of dietary intake by the 24 $\mathrm{h}$ recall EPIC SOFT program--the Norwegian calibration study. Eur $J$ Clin Nutr 2003;57:107-13. 